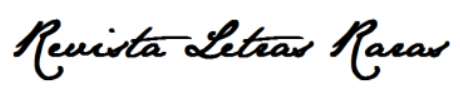

ISSN: $2317-2347$ - v. 6, n. 2 (2017)

\title{
Mulher, identidade e escrita em textos francófonos do Magrebe ${ }^{1}$ / Woman, identity, writing in francofone texts of Magreb
}

\author{
Josefina Bueno Alonso*
}

\begin{abstract}
RESUMO
Ultimamente, a crítica pós-colonial permitiu não apenas abrir uma via "mundial" às literaturas francófonas, mas também permitiu a análise de textos de mulheres no âmbito da teoria pós-colonial e da teoria feminista. Este trabalho visa a uma abordagem da escrita de algumas romancistas originárias do Magrebe, a partir da perspectiva da teoria feminista pós-colonial e do conceito de "sujeito nômade" enunciado pela filósofa feminista Rosi Braidotti (1994). Após algumas reflexões sobre a escrita de mulheres e o discurso sobre a identidade resultante dela, analisarei mais particularmente a escrita de Malika Mokeddem como representante de um percurso; percurso fictício ou real, a escrita simboliza por um lado, a revolta, a fuga, mas ela adquire igualmente um aspecto vital, um território de exílio e de errância, metáfora desse nomadismo existencial sinalizado por Braidotti (1994). No interior do corpus dos textos de mulheres, situarei a escrita de Malika Mokkedem como um referencial de uma nova escrita de mulher: entre magrebinidade e feminilidade nós vemos a desconstrução de estereótipos de gênero e uma reinterpretação do sujeito mulher.
\end{abstract}

PALAVRAS-CHAVE: Literatura pós-colonial; Gênero; Magrebe

\section{ABSTRACT:}

Lately, postcolonial criticism has not only opened a worldwide branch to francophone literatures, but has also allowed to study women's texts at the junction of postcolonial theory and feminist theory. The hereby article offers an approach of some Magreb women writers from the postcolonial feminist theory perspective and from the "nomadic subject» stated by the feminist philosopher Rosi Braidotti. After a reflection on women writing and the discourse of identity resulting from it, I will analize thoroughly Malika Mokeddem's writing as a representative of a path; real or ficticious path, the writing symbolizes on one hand the revolt, the escape but on the other hand it also gets a vital aspect, turning out to be an exile and errant territory, metaphor of existential nomadism mentioned by Braidotti. Inside women's texts, I'll situate Malika Mokeddem's texts as a reference of a new women writing: between feminity and magrebinity we attend at the deconstruction of stereotypes of gender and at the reinterpretation of the Woman subject.

KEYWORDS : Postcolonial literature; Gender; Magreb

\section{Escrita de mulheres}

\footnotetext{
${ }^{1}$ Este artigo foi resultado de uma conferência pronunciada na UNED (Madrid) em abril de 2004 em um seminário sobre "O romance francês e francófono: temas e autores contemporâneos".

* Professora de filologia francesa da Universidade de Alicante. Especialista em literaturas africanas. Departamento de Filologias Integradas. E-mail: jbueno@ua.es.

Tradução do artigo cujo título original é: "Femme, identité, écriture dans les textes francophones du Maghreb", publicado na Revista Thélème - Revista Complutense de Estudios Franceses. Traduzido por Maria Rennally Soares da Silva (doutoranda pelo Programa de Pós-Graduação em Literatura e Interculturalidade - UEPB), endereço eletrônico: rennally.fr@hotmail.com, Déborah Alves Miranda (mestranda pelo Programa de Pós-Graduação em Linguagem e Ensino - UFCG), endereço eletrônico: deborah.alves79@gmail.com) e Lucas Geovani Silva Queiroz (Graduando de Letras Língua Inglesa UEPB) endereço eletrônico: lucasgsq@msn.com.
} 


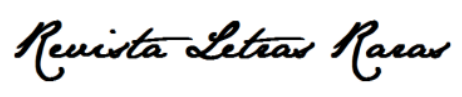

ISSN: 2317-2347 - v. 6, n. 2 (2017)

Nos últimos anos, os textos de mulheres têm se constituído em um corpus importante no interior da literatura pós-colonial francófona. A escrita das mulheres não faz apenas referência à oposição binária masculino/feminino, mas a uma escrita entre outras; aquela que, como destaca Michel Laronde (1996), mesmo que utilize uma linguagem standard, leva em conta as imbricações linguísticas e culturais e contesta a norma canônica. A escrita de mulheres seria, -por que não-, uma "escrita descentrada", no interior desse contexto que representam as literaturas francófonas das antigas colônias. Proponho aqui a análise de textos de mulheres do momento no qual a pertença ao sexo feminino marca a produção e a recepção desses textos ${ }^{2}$.

A crítica pós-colonial, por exemplo, afirma que a condição de colonizada marcou o texto para torná-lo a representação cultural de um processo de contestação e de resistência, a subversão de uma herança cultural e literária da metrópole; essa crítica também mostra que a condição do colonizado favoreceu a aparição de práticas textuais que se definem pelo fato de colocar em jogo a experiência da colonização e da independência. Sob a ótica pós-colonial, os textos do Magrebe manifestam as relações por vezes difíceis ou até mesmo contraditórias entre a França e o Magrebe, a herança histórica, a hegemonia cultural... no seio de uma sociedade europeia contemporânea. Minha análise se centra então sob os textos de mulheres no seu contexto histórico e em relação com a língua e a cultura central, bem como as relações que eles têm com sua cultura de origem, sendo analisados a partir da perspectiva europeia, lugar de onde eles procedem.

Analisar os textos de mulheres em meio à teoria pós-colonial e à feminista nos leva a citar brevemente algumas coincidências entre a crítica pós-colonial e a crítica feminista; citamos, dentre outras, a analogia estabelecida entre a situação marginal ou subordinada da mulher e a do colonizado; as propostas similares das duas teorias tais como dar voz aqueles ou aquelas que estão na invisibilidade, a desconstrução da autoridade canônica (contestação da neutralidade dos "grandes textos" e de suas ideologias), o combate ao universal masculino-ocidental que contribuiu para a percepção

\footnotetext{
${ }^{2}$ Seria curioso analisar a qual ponto o paratexto definido por Genette marca a recepção destes textos. Malika Mokeddem sinala o perigo de guetolização [referente a gueto] sendo mulher originária do Magrebe: "Ser mulher, Argelina e romancista se torna algo emblemático. Vejo muito mais um perigo do que um assunto de satisfação. Há nisso um risco de julgamento caricatural, logo redutor. Da mesma forma que eu não quis que me fechassem em um gueto, no que concerne ao mundo editorial, não gosto, não mais, que coloquem meus livros em no lugar da generalização. Cabe a nós combater os clichês!” (HELM, 2000, p. 28).
} 


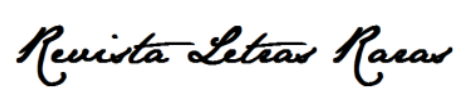

ISSN: 2317-2347 - v. 6, n. 2 (2017)

dos textos pós-coloniais e os textos de mulheres como os fatos anedóticos, por vezes simples satisfação de um desejo de exotismo. Tanto a teoria pós-colonial quanto a teoria feminista tiveram como objetivo transformar a condição do colonizado e/ ou da mulher de simples objeto ao status inteiramente de sujeito.

Contudo, ocorreram algumas dissidências no seio deste suposto grupo de mulheres, pois esta eventual "homogeneidade" não conseguia abranger as particularidades - especialmente as étnicas, socioculturais... -. A partir dos anos 70, algumas vozes se ergueram - principalmente na crítica anglo-saxônica - contra uma teoria que repousava excessivamente sob a "branquidão" e ocidentalização. Este "outro feminismo" centrou a maior parte de suas críticas sob uma teoria feminista excessivamente eurocentrista e etnocentrista (MOHANTY; SPIVAK, 1991) que escondia uma forma de colonização:

(...) no contexto da hegemonia da Academia Western na produção e disseminação de textos, e no contexto do imperativo legitimador do discurso humanista e científico, a definição da "mulher do terceiro mundo" como um monólito poderia muito bem enquadrar-se na maior praxe econômica e ideológica da investigação científica e do pluralismo «desinteressados», que são as manifestações superficiais de uma colonização econômica e cultural latente do "mundo não ocidental" (MOHANTY, 1991, p. 74). ${ }^{3}$

Nos últimos decênios, com base nas filosofias pós-estruturalistas e da pósmodernidade, a Alteridade reapareceu. Não se trataria mais do Outro sexuado ou feminilizado - resultado da oposição binária -, mas do Outro do ponto de vista étnico, social etc. Numerosas foram as vozes que contestaram a pertença mulher como um todo homogêneo. Os fluxos migratórios, a condição do neocolonialismo vivido no Ocidente pelas populações imigrantes, reforçaram o desejo de uma especificidade que se afasta cada vez mais do lugar "branco" e eurocêntrico. Diversas filosofias, críticas literárias que levantaram a não-unidade do Sujeito Mulher, mas a multiplicidade da mesma. Em meio a essas vozes citamos a filósofa americana Judith Butler (1990), que em seu ensaio tenta

\footnotetext{
${ }^{3}(\ldots)$ In the context of the hegemony of the Western scholarly etablishment in the production and dissemination of texts, and in the context of the legitimating imperative of humanistic and scientific discourse, the definition of the «third world woman» as a monolith might well tie into the larger economic and ideological praxis of «desinterested» scientific inquiry and pluralism wich are the surface manifestations of a latent economic and cultural colonization of the «non-western world» (MOHANTY 1991, p. 74).
} 


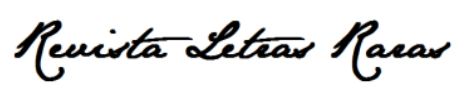

ISSN: 2317-2347 - v. 6, n. 2 (2017)

desconstruir a oposição binária masculino/feminino bem como a universalidade da condição feminina que remete necessariamente a uma concepção essencialista da mulher: "a insistência na coerência e na unidade da categoria das mulheres rejeitou efetivamente a multiplicidade de interseções culturais, sociais e políticas nas quais a série concreta de “mulheres “é construída.” (BUTLER 1990, p. 15)․

Por sua vez, Naomi Schor (1995) rejeita não apenas o universalismo feminino, mas recusa igualmente a noção de uma homogeneidade feminina transcultural:

A feminista pós-modernismo está profundamente implicada nesta condenação do universal, do universalismo e da universalização. Não só a noção de que pode haver algum anátema compartilhado da natureza feminina para as feministas pós-modernistas, mas mesmo a noção de que exista algo como um assunto feminista transcultural é fortemente contestado (SCHOR, 1995, p. 16) 5

Esta recusa ao estabelecimento de uma homogeneidade feminina leva à noção de multiplicidade construída pela filósofa Rosi Braidotti (2000). Ela destaca alguns aspectos importantes de uma nova concepção da mulher tais como a não-unidade do Sujeito Mulher, a análise da subjetividade feminina a partir de um conjunto estratificado de variantes (a raça, a etnia, a classe social...) bem como a ideia de que cada mulher se enuncia a partir da sua localização no tempo, na história (BRAIDOTTI, 2000). Esses aspectos se tornam particularmente importantes no caso das escritoras do Magrebe; essas novas vozes que se erguem no interior da literatura francófona reúnem os aspectos desta "consciência nômade feminista" enunciada por Braidotti (2000) e, do meu ponto de vista, completam a situação atual de confronto em que se encontra o pensamento feminista.

\section{0 discurso sobre a identidade}

Falar de mulher, de escrita e do Magrebe remete ao discurso teórico sobre identidade a partir da perspectiva da teoria feminista. De uma forma geral, os textos

\footnotetext{
${ }^{4} \ldots$ the insistence upon the coherence and unity of the category of women has effectively refused the multiplicity of cultural, social, and political intersections in which the concrete array of «women» are constructed. (BUTLER 1990, p. 15).

${ }^{5}$ And feminist postmodernism is deply implicated in this condemnation of the universal, universalism and universalizing. Not only is the notion that there might exist some shared feminine nature anathema to feminist postmodernists, but even the notion that there might exist something like a transcultural feminist subject is strongly contested (SCHOR, 1995, p. 16).
} 


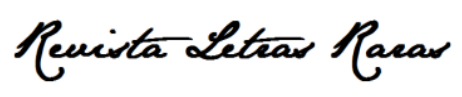

ISSN: 2317-2347 - v. 6, n. 2 (2017)

francófonos tendem a desconstruir uma identidade fixa. Na poética francófona o discurso sobre identidade aparece ao lado da atividade criadora, a escrita. Os textos de mulheres refletem não apenas o confronto inerente à identidade pós-colonial francófona, mas também o confronto diante da condição do indivíduo sexuado. Por exemplo, no contexto do Magrebe é interessante destacar a ambiguidade própria ao discurso sobre o gênero: não esqueçamos que, para várias mulheres, a França representa o país colonizador, mas ela representa também em um sentido literal ou figurado, uma libertação. A França e a língua francesa representaram o acesso à escola, à universidade; como sinaliza Carine Bourget (2002), na época colonial, a libertação da mulher era associada ao colonialismo, porém, agora, ela é associada à rejeição ao islam.

É preciso igualmente lembrar que nós nos situamos em um contexto cultural marcado pela autoridade patriarcal sustentada pelo discurso religioso - a religião muçulmana. O espaço da escrita se torna então o agente que permite a desconstrução de estruturas que agem no estado simbólico segundo a terminologia de Bourdieu ${ }^{6}$; mas a escrita se torna igualmente o lugar que permite a reconstrução de uma identidade marcada pelo sexo e por um desejo de representação em relação ao Outro normatizado.

É preciso situar o ponto de partida no conceito da identidade fragmentada, híbrida (BHABHA, 1994), marcada pela noção deleuziana de Rizoma, recusa de uma raiz única e pela noção de diverso definida pelo escritor e ensaísta martiniquense Édouard Glissant. Vemos cada vez mais, vários discursos que, a partir de diferentes disciplinas (literatura, filosofia, antropologia...) nos mostram uma definição da identidade como um conjunto de pertenças não fixas, variáveis em função do lugar, do momento histórico etc. Malika Mokeddem define a si mesma como uma "expatriada" rejeitando toda raiz que a prende:

Duas palavras me eriçam... "nacionalidade" e "raízes"... Tenho certeza de que não é preciso negar nada para se florescer. Mas não quero que me tranquem em nenhuma fronteira qualquer que seja. Minha avó dizia: "Apenas as palmeiras têm raízes. Nós, nós somos nômades. Nós temos uma memória e pernas para caminhar." Eu fiz disso o meu lema de vida. (HELM, 2000, p. 32) ${ }^{7}$.

\footnotetext{
6 Bourdieu qualifica como "violência simbólica" a dominação masculina que é imposta, submissão paradoxal, violência doce, insensível, invisível para as suas vítimas, que se exerce essencialmente pelas vias puramente simbólicas da comunicação e do conhecimento ou, mais precisamente, do desconhecimento, do reconhecimento ou, ainda, do sentimento (BOURDIEU, 1998).

${ }^{7}$ Texto original: Deux mots me hérissent « nationalité » et « racines »... Je sais profondément qu'il ne faut rien renier pour s'épanouir vraiment. Mais je ne veux pas qu’on m’enferme dans quelque frontière que ce
} 


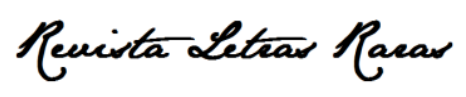

ISSN: $2317-2347$ - v. 6, n. 2 (2017)

O discurso das mulheres não sendo desprovido do seu aspecto social, não se trataria mais de definir o ser mulher a partir de características fixas, mas muito mais de conceber que o sujeito mulher se define em função da representação do seu poder, consciente de sua condição social, longe de assumir uma posição essencialista.

Simone de Beauvoir continua sendo uma referência para um grande número de escritoras do Magrebe. A referência a Segundo sexo aparece várias vezes nos romances de Malika Mokeddem e também em outras escritoras do Magrebe como a primeira lição para a libertação das mulheres; aprendizagem à qual contribuem as diferentes gerações de mulheres que se encontra nos romances com fortes ecos autobiográficos ${ }^{8}$ : “Trabalho duro e leio tarde. Leituras importantes balizam minhas insônias: Rimbaud, Colette, Giono, Sartre, Beauvoir, autora de Segundo sexo, cuja obra me abre os horizontes e me confronta." (MOKEDDEM, 2003, p. 165) ${ }^{9}$.

$\mathrm{Na}$ atualidade assistimos ao nascimento de novas contestações em um contexto francófono em relação à "identidade mulher". O sucesso dos emblemas do feminismo francês se encontra atualmente em um impasse devido a duas razões: por um lado, o feminismo francês (Beauvoir, Irigaray ${ }^{10} \ldots$... ignorou as mulheres originárias de outras etnias ou culturas, outros grupos sociais; por outro lado, a proclamação do universalismo configurado segundo o modelo ocidental e branco suscitou críticas em torno de uma identidade hegemônica ocidental, ignorando a confluência da categoria mulher com outras categorias supracitadas. Desse ponto de vista, os textos de mulheres do Magrebe representariam essas "outras vozes" marcadas pela não-ocidentalidade e pela nãocristandade, mas no interior do contexto europeu - o contexto francês.

A teoria feminista se vê então confrontada com um discurso social presente na França e em outros países europeus que contam com uma numerosa população magrebina; falo da reivindicação de uma identidade diferente da identidade hegemônica

soit. Ma grand-mère disait : « Il n’y a que les palmiers qui ont des racines. Nous, nous sommes nomades. Nous avons une mémoire et des jambes pour marcher ». J'en ai fait ma devise. (HELM, 2000, p. 32).

${ }^{8}$ A obra de Simone de Beauvoir representou durante muito tempo, para a teoria feminista, os valores de um universalismo francês bem diferente das tendências da teoria feminista americana (SCHOR, 1995).

${ }^{9}$ Texto original: Je bûche et je lis tard. Des lectures importantes balisent mes insomnies : Rimbaud, Colette, Giono, Sartre, Beauvoir dont le deuxième sexe m'ouvre des horizons et me conforte. (MOKEDDEM, 2003, p. 165).

${ }^{10}$ Subinha-se uma maior sensibilidade para a identidade cultural em uma de suas obras Entre Orient et Occident. 


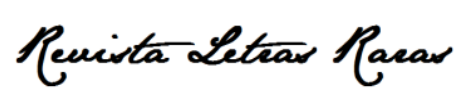

ISSN: 2317-2347 - v. 6, n. 2 (2017)

europeia $^{11}$, marcada especialmente pela pertença a uma religião diferente e pulverizada pelas dificuldades de integração ${ }^{12}$. É assim que o discurso das mulheres é submisso às tensões internas e externas que tornam ainda mais difícil a definição do "ser mulher", o fato de "se identificar mulher". Essas novas contestações se resumem e foram simbolizadas através do debate na França em torno da problemática do véu, por vezes metonímia da figura do estrangeiro ocidental; assim sublinha a escritora tunisiana Fawzia Zouari em seu último ensaio que oferece uma excelente reflexão sobre a problemática do véu no contexto francês:

$\mathrm{O}$ islam velado se enxerga como portador de outro ponto de vista e contesta o feminismo em tamanho único. Pois se as muçulmanas recorrem a um véu, não é necessariamente para duplicar sua afirmação identitária, tampouco para se identificar com um Islã, mas para reivindicar, desta vez, a parte que falta de sua francidade (ZOUARI, 2004, p. 130-142). ${ }^{13}$

Como representação dessas “outras vozes” é preciso citar igualmente os trabalhos da socióloga marroquina Fatema Mernissi - referencial obrigatório no que concerne aos debates em torno do feminismo e da condição da mulher muçulmana ${ }^{14}$.

\section{Escrever, para uma mulher}

O poder criador é uma expressão de atividade lúdica. Não há finalidade, ele abre os horizontes, transforma as visões. Ele é, antes de tudo, jogo e prazer. (...) Todo trabalho criador é essencialmente subversivo, toda atividade que se apoia sobre a imaginação, o sentido do jogo, o prazer da pesquisa é subversivo. O exercício fundamental da criação reúne o exercício fundamental das liberdades humanas (HORER, 1973, p. $14)^{15}$.

\footnotetext{
11 «A identidade europeia conseguiu aperfeiçoar historicamente o truque que consiste em se passar como norma, o centro desejável, confinando todos os outros à posição de periferia» (Braidotti 1994: 10).

Texto original: "European identity has managed historically to perfect the trick that consist in passing itself off as the norm, the desirable center, confirning al « others » to the position of periphery » (BRAIDOTTI, 1994, p. 10).

12 Ultimamente influenciada pela sombra do terrorismo islâmico.

13 Texto original: L'islam voilé se veut porteur d'un autre point de vue et conteste le féminisme à taille unique. (...) Car si les musulmanes recourent à un voile ce n'est pas toujours pour doubler leur affirmation identitaire, ni pour s'identifier à un islam d'ailleurs, mais pour revendiquer, cette fois, la part manquante de leur francité. (ZOUARI, 2004, p. 130-142.)

${ }^{14}$ Ver também os trabalhos da socióloga Nilufer Gole.

${ }^{15}$ Le pouvoir créateur est une expression de l'activité ludique. Il n'a pas de finalité, il ouvre les horizons, transforme les visions. Il est, avant tout, jeu et plaisir. (...) Tout travail créateur est essentiellement subversif, toute activité qui s'appuie sur l'imagination, le sens du jeu, le plaisir de la recherche est subversive.
} 


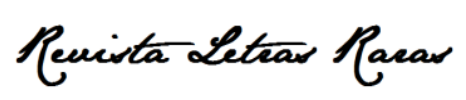

ISSN: 2317-2347 - v. 6, n. 2 (2017)

A escrita permite ultrapassar os códigos. Desde que tu te deixas conduzir além desses códigos, teu corpo cheio de temor e de alegria, as palavras se distanciam, tu não estás mais preso em seus planos de construções sociais, tu não andas mais entre muros, os sentidos se destroem, o mundo dos raios explode, os ares passam, os desejos fazem saltar as imagens, as paixões não o são mais. (CIXOUS, 1986, p. 61). ${ }^{16}$

Eu enegreci páginas de cadernos, de uma escrita furiosa. Sem essas salvas de palavras, a violência do país, a desesperança da separação teriam me explodido, pulverizado (...). Faço parte daqueles que, fixam em uma página ou uma tela, respondem por críticas severas aos infortúnios da vida, às loucuras das facas, aos transes das kalachnikovs (MOKEDDEM, 2003, p. 59). ${ }^{17}$

Estas citações tiradas de vários criadores (pintor, escritoras) sublinham os principais rochedos da atividade criadora: se trata de uma atividade lúdica, subversiva e que reforça as liberdades humanas. Escrever, para uma mulher ou homem após o debate das lutas pela independência resultou ainda mais em uma posição engajada. Para as mulheres isso se elevou como consequências do imenso peso da tradição e dos preconceitos religiosos que marcaram a existência das mulheres. Para numerosas escritoras originárias do Magrebe, a escrita traz consigo a impressão de uma identidade marcada por uma falta, particularmente a ausência da língua materna ${ }^{18}$. É assim que a escrita reagrupa todos os elementos identitários das mulheres, pois permite um retorno às origens tão logo essas foram em algum momento dilaceradas. Assia Djebar é uma das escritoras que menciona esse retorno às origens, - como sinala C. Chaulet-Achour (1999) -, ela afirma experimentar uma mutilação se exprimindo em francês:

Escrever em língua estrangeira, fora da oralidade das duas línguas da minha região natal - o berbere das montanhas do Dahra e o árabe da

L'exercice fondamental de la création rejoint l'exercice fondamental des libertés humaines. (HORER 1973, p. 14).

${ }^{16}$ L'écriture permet de dépasser les codes. Dès que tu te laisses conduire audelà des codes, ton corps plein de crainte et de joie, les mots s'écartent, tu n'es plus enserrée dans les plans des constructions sociales, tu ne marches plus entre les murs, les sens s'écroulent, le monde des rails explose, les airs passent, les désirs font sauter les images, les passions ne sont plus. (CIXOUS 1986, p . 61).

${ }^{17}$ Je noircis des pages de cahiers, d'une écriture rageuse. Sans ces salves de mots, la violence du pays, le désespoir de la séparation m'auraient explosée, pulvérisée. (...) Je fais partie de ceux qui, cloués à une page ou un écran, répondent par des diatribes aux délabrements de la vie, aux folies des couteaux, aux transes des kalachnikovs. (MOKEDDEM 2003, p. 59).

${ }^{18}$ Sinalamos a presença da língua nos títulos das últimas narrativas de autores do Magrebe: La disparition de la langue française, Assia Djebar, 2003; Je ne parle pas la langue de mon père, Leïla Sebbar, 2003. 


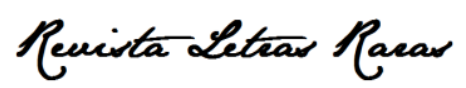

ISSN: $2317-2347$ - v. 6, n. 2 (2017)

minha cidade -, escrever me trouxe aos gritos das mulheres surdamente revoltadas da minha infância, na minha única origem. Escrever não mata a voz, mas a desperta, sobretudo para ressuscitar as muitas irmãs desaparecidas. (DJEBAR, 1995, p. 229) ${ }^{19}$.

Constatamos que na produção de Malika Mokeddem, a escrita ocupa um lugar privilegiado sobre o plano da diegese - no interior de suas narrativas de ficção - bem como sobre o plano extradiegético - o que a escrita representa para a autora e como ela exprime, por exemplo, sua narrativa autobiográfica La transe des insoumis. A reflexão sobre a escrita ocupa a maior parte de suas personagens de ficção que se tornam a voz em off da própria escritora, a mulher engajada. Da realidade à ficção, a escrita e os livros adotam um caráter vital. Através de suas entrevistas, por exemplo, nós descobrimos que os livros ocupam um lugar importante em sua existência:

Cada ano, a aproximação dos quatro meses e meio de férias de verão me imergia, realmente, em um estado de aflição. Como atravessar o infernal verão saariano quando se é uma menina e quando a pobreza proíbe toda fuga para lugares mais clementes? Quando o despotismo das temperaturas e uma tradução misógina conjugam seus efeitos para excluir as meninas da rua e das distrações? Eu havia me tornado anoréxica mas devorava os livros. E antes de atravessar o maldito verão, eu me inquietava de minhas reservas e fazia provisão de vida para mim. O corpo recolhido no silêncio dos livros, as mãos agarradas na imobilidade de suas pagnes $^{20}$, os olhos levados pelas ondas de suas palavras, eu ia ao encontro de Sartre e de Beauvoir, Giono e Colette, Tolstoï, Dostoïevski, Gorki, Kafka, Falkner. (HELM, 2000, p. 23). ${ }^{21}$

Paralelamente, todos os seus personagens de ficção se refugiam na leitura e na escritura afim de evadir de uma realidade hostil:

\footnotetext{
19 Texto original: Écrire em langue étrangère, hors de l'oralité des deux langues de ma région natale - le berbère des montagnes du Dahra et l'arabe de ma ville -, écrire m'a ramené aux cris des femmes sourdement révoltées de mon enfance, à ma seule origine. Écrire ne tue pas la voix, mais la réveille, surtout pour ressusciter tant de sœurs disparues. (DJEBAR, 1995, p. 229).

${ }^{20}$ Nota dos tradutores: Pagne é um pano feito de tecido ou de material vegetal trançado produzido na África.

${ }^{21}$ Texto original: Chaque année, l'approche des quatre mois et demi de vacances estivales me plongeait, véritablement, dans un état de détresse. Comment traverser l'infernal été saharien quand on est une fille et quand la pauvreté interdit toute évasion vers des lieux plus cléments ? Quand le despotisme des températures et une radiation mysogine conjuguent leurs effets pour exclure les filles de la rue et des distractions ? J'étais devenue anorexique mais je devorais les livres. Et avant de franchir le maudit été, je m'inquiétais de mes réserves et faisais provision de mes vivres à moi. Le corps rencogné dans le silence des livres, les mains agrippées à l'immobilité de leurs pagnes, les yeux portés par les flots de leurs mots, j'allais à la rencontre de Sartre et de Beauvoir, Giono et Colette, Tolstoï, Dostoïevski, Gorki, Kafka, Falkner. (HELM, 2000, p. 23).
} 


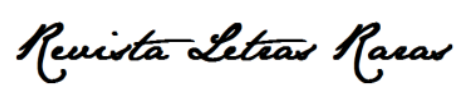

ISSN: $2317-2347$ - v. 6, n. 2 (2017)

A escola, o saber, lhe abririam uma escapatória até então inimaginável no impasse das fatalidades femininas. Eles a tinham arrastado à um destino medieval para precipitá-la, sozinha, em pleno século XX. (MOKEDDEM, 1990, p. 267). ${ }^{22}$

Observamos que a recusa social à qual foi submetida a mulher se recupera com a prática da escrita. A instrução é o único remédio para uma via livre tal como mostra a personagem da professora francesa que, sob a nominação genérica de institutrice, se encontra em um bom número de seus romances e encoraja as personagens meninas a persistir em seus estudos. Leïla, por exemplo, compreendeu cedo que a libertação só vem pelo lado da instrução, do acesso à educação:

Giz, lousa, pluma, cadernos, livros... (...) Um universo às antipodes daquele que aprisionava sua mãe? Plumas, caderno e livros iam se tornar suas únicas rotas de fuga fora de todos os aprisionamentos: as ordens da sua mãe, as tarefas domésticas, uma tradição enferrujada e trancada, o nada das imensidões. Mais tarde ainda, seriam suas armas e meios de resistência. (MOKEDEEM, 1990, p. 124) ${ }^{23}$.

O aspecto vital da escrita preenche as faltas do indivíduo. É assim que muitas vezes é interpelada a textualidade das palavras: "Eu me farto da única liberdade ao meu alcance, a leitura. (...) As palavras desconhecidas são os maiores passos da minha fuga. Elas me deixam livre do sentido acordado à sua grafia, à sua sonoridade e me embriago mais." (MOKEDDEM, 2003, p. 142) ${ }^{24}$.

Quase todas as personagens de Malika Mokeddem se caracterizam pelo seu trato solitário, seu caráter de excepcionalidade reforçado por uma inclinação inata para a escrita, a leitura. Uma consequência direta desse trato solitário e da exceção é sua situação

\footnotetext{
22 Texto original: L’école, le savoir lui ouvraient une échappée jusqu'alors insoupçonnée dans l'impasse des fatalités féminines. Ils l'avaient arrachée à un destin moyennageux pour la précipiter, seule, en plein milieu du XXe siècle. (MOKKEDEM, 1990, p. 267).

${ }^{23}$ Texto original: Craies, ardoise, plume, cahiers, livres... (...) Un univers aux antipodes de celui qui emprisonnait sa mère ? Plumes, cahier et livres allaient devenir ses seules lignes de fuite hors de tous les enfermements : les ordres de sa mère, les tâches ménagères, une tradition rouillée et verrouillée, le néant des immensités. Plus tard encore, ils seraient ses armes et moyens de résistance. (MOKEDDEM, 1990, p. 124).

${ }^{24}$ Texto original: Je me gave alors de la seule liberté à ma portée, la lecture. (...) Les mots inconnus sont les plus grandes foulées de ma fugue. Ils me laissent livre du sens accordé à leur graphie, à leur sonorité, et me grisent davantage. (MOKEDDEM, 2003, p. 142.)
} 


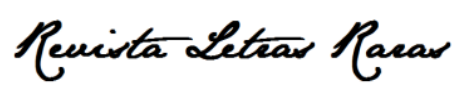

ISSN: 2317-2347 - v. 6, n. 2 (2017)

de exílio permanente que reflete igualmente a situação do escritor e da mulher: "É um hábito de expatriar e de insônia de se contar histórias? (...) É uma forma de existir apesar e contra tudo? (MOKEDEEM, 2003, p. 29) ${ }^{25}$. Essa escrita-exílio se torna, por um lado, o status do sujeito escritor e, por outro lado, o topo ideal onde se aloja o único patrimônio da memória nômade ${ }^{26}$. Essa condição de desenraizadas, de nômades em permanência faz da escrita a via de expressão desse sujeito nômade que se torna a escritora magrebina. Esse desenraizamento literal ou metafórico nos conduz a uma escrita território de exílio que encontramos em outras escritoras como a franco-argelina Leïla Sebbar:

Hoje tomo consciência do vazio ao qual sou confrontada. (...) Não me sinto mais de comunidade, de família, de espírito. (...) Também, como, onde me situar? Me parece às vezes que a minha única terra, talvez também para você, é a escrita, a escola, os livros. (SEBBAR, 1986, p. $130-131)^{27}$.

Essa situação de exílio permanente que invade as personagens dos seus romances e que se inscreve igualmente como o status existencial da escritora simboliza a metáfora da mobilidade, a fuga através de uma realidade desprovida de malefícios. Um dos tratos importantes da escrita de Malika Mokeddem é o desejo de apagar os estereótipos literários que fizeram dos romances de mulheres do Magrebe um lamento mítico da condição feminina. Em seus romances, encontramos uma larga panóplia de personagens femininas, de toda condição, idade, nacionalidade... os grandes males da humanidade não são mais visados (o antissemitismo, a tradição misógina, a escravatura, a guerra etc.) nesse percurso entre a História recente da França e da Argélia através de um tipo de escrita militante em um grande desafio, tal como afirma: “A romancista se apodera das palavras e dos males - para tentar cuidar-se, em todos os sentidos do termo!" (HELM, 2000, p. $32)^{28}$. Não é por acaso que ela sacrificou sua carreira de nefrologista pela escrita e se ela

\footnotetext{
${ }^{25}$ Texto original: «Est-ce une habitude d'expatriée et d'insomniaque de se raconter des histoires ? (...) Estce une façon d'exister envers et contre tout? (MOKEDDEM, 2003, p. 29).

${ }^{26}$ Notar a impressão que sua origem nômade projeta em suas narrativas e romances.

27 Texto original: Je prends conscience aujourd'hui du vide auquel je suis confrontée. (...) Je ne me sens plus de communauté, de famille, d'esprit. (...) Aussi, comment, où me situer? Il me semble parfois que ma seule terre, peut-être aussi, pour toi, c'est l'écriture, l'école, les livres. (SEBBAR, 1986, p. 130-131).

${ }^{28}$ Texto original: La romancière s'empoigne des mots et des maux - pour tenter de se soigner elle-même, dans tous les sens du terme! (HELM, 2000, p. 32).
} 


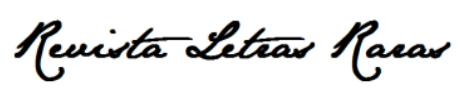

ISSN: 2317-2347 - v. 6, n. 2 (2017)

escolheu um tipo de compatibilidade entre a escrita e a medicina como duas versões de sua atitude engajada, de uma vontade de cura e de uma necessidade própria: "Me imaginei durante muito tempo toubid dos nômades (...) em Montpelier me tornei toubib dos nômades do meu tempo, os imigrantes" (HELM, 2003, p. 150) ${ }^{29}$.

\title{
3.1 O poder da escrita
}

As mulheres são conscientes do poder simbólico da escrita e das palavras. Marina Yaguello sublinha nesse sentido que a relação com a língua passa pela sua relação com a sociedade:

\begin{abstract}
A língua não é feita unicamente para facilitar a comunicação; ela permite também a censura, a mentira, a violência, o desprezo, a opressão, bem como o prazer, a fruição, o jogo, o desafio, a revolta. (...) A língua é um espelho cultural que fixa as representações simbólicas e produz eco dos preconceitos e dos estereótipos, ao mesmo tempo em que alimenta e entretém estes. (YAGUELLO, 1978, p. 7-8) ${ }^{30}$.
\end{abstract}

A escrita se torna então o lugar de resistência, o combate contra um discurso tradicionalmente transmitido por uma cultura e uma tradição misógina. Essa tradição misógina é transmitida pela educação e pelo discurso religioso. O discurso religioso - no sentido de doxa - se assimila ao discurso transmitido geralmente pelos homens. Quer seja em um contexto europeu ou magrebino, a atividade criadora foi concebida como libertadora ou até mesmo denunciadora de um espaço privado reservado às mulheres em oposição ao "espaço público" tradicionalmente reservado aos homens. Se identifica nas romancistas um desejo de combater o peso da tradição. Nesse sentido, encontramos nas narrativas de Malika Mokeddem numerosas críticas à figura da mãe, continuadora desta educação misógina; ela simboliza a guardiã da tradição, a obediência aos modos que perpetuam o status de inferioridade da mulher: “(...) mãe, avó e tias se encarregarão mais

\footnotetext{
29 Texto original: Je m'étais longtemps imaginée toubib des nomades (...) à Montpellier je suis devenue des nomades de mon temps, les immigrés (HELM, 2003, p. 150).

${ }^{30}$ Texto original: La langue n'est pas faite uniquement pour faciliter la communication ; elle permet aussi la censure, le mensonge, la violence, le mépris, l'oppression, de même que le plaisir, la jouissance, le jeu, le défi, la révolte. (...) La langue est un miroir culturel qui fixe les représentations symboliques, et se fait l'écho des préjugés et des stéréotypes, en même temps qu'il alimente et entretient ceux-ci. (YAGUELLO, 1978, p. 7-8).
} 


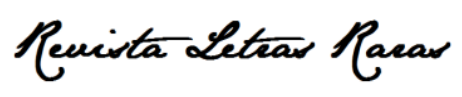

ISSN: 2317-2347 - v. 6, n. 2 (2017)

tarde de repassar às suas filhas os seus traumas para reforçar em suas cabeças os seus sentimentos de inferioridade $^{31}$ (MOKEDDEM, 2003, p. 117) ${ }^{32}$.

Outro fator que reforça a Tradição continua sendo o discurso religioso. Este, por exemplo, é questionado em relação à passividade de uma divindade poderosa que aceita a segregação injusta entre os homens e mulheres. É o caso de Malika Mokeddem que, sem referência explícita ao Corão, nem à religião propriamente dita, interpela a divindade se lamentando do peso de uma tradição masculina que marca o destino das mulheres. Suas narradoras, personagens geralmente jovens ou adolescentes, se questionam sobre o destino - por vezes injusto e defendido pela autoridade - das mulheres, resultado de uma educação sexista. A ironia do tom é o elemento dominante que surge da reflexão ingênua de uma menina, Leïla, que desde cedo se dá conta das diferentes educações que recebem os meninos, com relação às meninas:

Pois aqui, o sol é uma divindade ainda mais cruel que Alá. Ele calcina tudo o que este último poupou, com a diferença de que, ele não precisa de bandos escravagistas zelosos para executar suas tarefas. O céu inteiro por trono, ele chega a dotar de beleza as tiranias que ele impõe aos humanos. (MOKEDDEM, 1990, p. 280). ${ }^{33}$

Em outro romance Le sièle des sauterelles, a narradora crescida em uma tribo de nômades ao Norte da África, se lamenta do destino das mulheres que se dedicam às tarefas domésticas desde o amanhecer até a noite, sem nenhum reconhecimento da parte dos seus parentes; mais do que uma crítica agressiva, nós assistimos a um ligeiro piscar de olhos com um tom não desprovido de ironia: "E, com tudo isso, Alá não os dispensa nem mesmo da oração! Baba, por quê esse tipo de infâmia? Chego a crer que Alá é apenas um conceito criado para legitimar uma injustiça secular." (MOKEDDEM, 1992, p. 257) ${ }^{34}$.

\footnotetext{
31 Texto original: ... mère, grand-mère et tantes se chargeront plus tard de ressasser à ces filles leur traumatisme à elles pour mieux leur enfoncer dans le crâne leur sentiment d'infériorité (MOJEDDEM, 2003, p. 117).

32 A representação da maternidade nas escritoras do Magrebe se integra no projeto de pesquisa "Mãe. Análises e estratégias oriundas da atualização das noções de maternidade e família. Uma perspectiva pluridisciplinar", que é resultado de uma resposta da parte do Ministério de Ciência e Tecnologia.

${ }^{33}$ Texto original : Car ici, le soleil est une divinité encore plus cruelle qu'Allah. Il calcine tout ce que ce dernier a épargné avec cette différence que, lui, il n'a nul besoin de cohortes esclavagistes zélés pour éxecuter ses besognes. Le ciel entier pour trône, il parvient à doter de beauté les tyrannies qu'il assène aux humains. (MOKEDDEM, 1990, p. 280).
} 


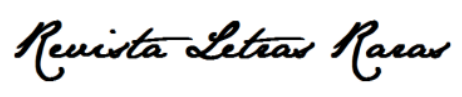

ISSN: 2317-2347 - v. 6, n. 2 (2017)

Encontramos, com frequência, nos romances das escritoras da religião como continuadora dessa tradição misógina; é o que vemos em Assia Djebar, quando descreve o lugar que ocupam as mulheres no momento de fazer as orações: "Na mesquita, no canto reservado às mulheres, uma erosão fez reagir seu ácido: entrar pela submissão, parece decidir a Tradição e não pelo amor. O amor que iluminaria a mais simples das encenações aparece perigoso." (DJEBAR, 1995, p. 191) ${ }^{35}$.

Conscientes do peso das palavras e do poder que acorda a escrita como contraponto a essa herança cultural, é interessante sinalar que o trabalho de reescrita do discurso religioso empreendido pelas mulheres. Assia Djebar retoma episódios religiosos nos quais é sublinhado o papel ativo das mulheres. É o caso do seu romance Loin de Médine onde a autora nos transporta até a Medina à época da morte do Profeta. São mulheres de l'entourage do fundador do Islam que ela nos fala, redescobrindo figuras de uma história ignorada: "Loin de Médine, esboçando retratos de homens e de mulheres muçulmanas, insiste sobre a irredutibilidade da mulher muçulmana em um modelo, e reivindica uma variedade de modos de viver o Islã e de construir o feminino" (BOURGET, 2002, p. 83-84) ${ }^{36}$. Essa tendência, realizada igualmente nos trabalhos da socióloga Fatema Mernissi, responde à revolta contra uma interpretação misógina do Islã e reivindica uma interpretação do feminino da religião afim de torná-la compatível com um status igualitário da mulher.

\subsection{A língua de escrita}

Um dos grandes paradoxos da literatura francófona do Magrebe foi utilizar a língua do colonizador para afirmar uma identidade cultural; citamos, por exemplo, as diferentes denominações que sucederam para qualificar esta literatura. É natural que as escritoras tenham partilhado essa esquizofrenia que implica em expressão de uma

\footnotetext{
${ }^{34}$ Texto original: Et, avec tout cela, Allah ne les dispense même pas de la prière ! Baba, pourquoi ce sort infâme? J'en arrive à croire qu'Allah n'est qu'un concept brandi pour légitimer une injustice séculaire. (MOKEDDEM, 1992, p. 257).

${ }^{35}$ Texto original: à la mosquée, dans le coin réservé aux femmes, une érosion a fait agir son acide: entrer par soumission, semble décider la Tradition, et non par amour. L'amour qu'allumerait la plus simple des mises en scène apparaît dangereux. (DJEBAR, 1995, p. 191).

${ }^{36}$ Texto original: Loin de Médine, en esquissant des portraits d'hommes et de femmes musulmanes, insiste sur l'irréductibilité de la femme musulmane en un modèle, et revendique une variété de modes de vivre l'Islam et de construire le féminin (BOURGET, 2002, p. 83-84).
} 


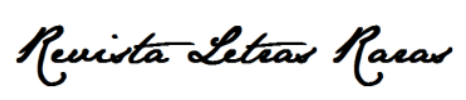

ISSN: 2317-2347 - v. 6, n. 2 (2017)

identidade específica que foi produzida a partir de uma língua secundária. Não é por acaso que Assia Djebar qualifica a língua francesa como "língua madrasta". No entanto é preciso sublinhar as conotações que a língua francesa oferece aos escritores. Entre outras, a língua francesa representa o acesso à instrução, à escrita, à emancipação feminina: “A língua francesa me lembra rebeliões, não apenas dos outros enquanto franceses, mas de outros continentes; Dickens, Tolstoï, Faulkner, Dostoïevski, etc., (...) o francês me ensinou a me defender, não apenas a gritar (HELM, 2000, p. 42) ${ }^{37}$.

No entanto, para Assia Djebar, a língua francesa se torna um tipo de véu que omite a intimidade mais profunda:

O francês é para mim uma língua madrasta. Qual é a minha língua mãe desaparecida, que me abandonou na calçada e depois fugiu?... Línguamãe idealizada ou mal-amada, entregue aos oficiais de feira ou aos carcereiros!... Sob o peso dos tabus que trago comigo como herança, me encontro desertada dos cantos de amor árabe. É para ter sido expulsa desse discurso amoroso que me faz achar árido o francês que emprego? (DJEBAR, 1985, p. 240) ${ }^{38}$.

A escrita de Malika Mokeddem não é desprovida da sua condição existencial. Ela carrega traços de uma oralidade herdada da sua origem nômade. Numerosos são os traços de oralidade: pluralidade de vozes, relatos, micronarrativas... em uma série de dicotomias tais como a oralidade/escrita; tradição árabe-muçulmana/realidade francesa; mundo précolonial/colonialismo; tradição/modernidade no centro das quais se insere uma nova condição da mulher escritora. Essas dicotomias representadas por um casal de mulheres, longe de se opor, se erguem em uma relação de cumplicidade e de sonoridade que se reflete em uma nova concepção da língua de escrita:

Me digo que não posso morder o seio que me alimentou, não posso trair uma coisa que está em mim. (...).

Eu não escolhi esta língua mas ela é minha - então digo isso quando tenho um público francês - é ela que veio me colonizar para a minha

\footnotetext{
${ }^{37}$ Texto original: La langue française en m'apportant les rébellions, pas uniquement des autres en tant que Français, mais des autres continents; Dickens, Tolstö̈, Faulkner, Dostoïevski, etc., (...) le français m'a appris à me défendre, pas seulement à crier (HELM, 2000, p. 42).

38 Texto original: Le français m'est langue marâtre. Quelle est ma langue mère disparue, qui m'a abandonnée sur le trottoir et s'est enfuie ? ...Langue-mère idéalisée ou mal-aimée, livrée aux hérauts de foire ou aux seuls geôliers !... Sous le poids des tabous que je porte en moi comme héritage, je me retrouve désertée des chants de l'amour arabe. Est-ce d'avoir été expulsée de ce discours amoureux qui me fait trouver aride le français que j'emploie ? (DJEBAR, 1985, p. 240).
} 


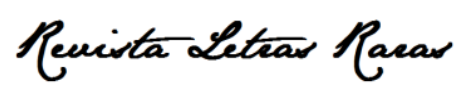

ISSN: $2317-2347$ - v. 6, n. 2 (2017)

felicidade - a língua, pelo colonizador - e agora por ela ter me possuído, é que ela faz parte de mim, sou eu que, no presente, vou colonizá-la e lhe dizer da complexidade da situação argelina e de 'argelinizá-la'. Então, foi assim que ela se tornou minha. (HELM, 2000, p. 42-43) ${ }^{39}$.

Observamos que o desejo de assimilação e de conquista da língua do Outro, da parte das primeiras gerações, desaparece. O troféu de guerra proclamado por Kateb Yacine durante as lutas pela independência acabou por edificar em Malika Mokeddem uma fortaleza do amor (MOKEDDEM, 2003, p. 131). No caso de Malika Mokeddem a escolha inconsciente da língua francesa se torna a voz / expressão - e porque não a afirmação - de alteridade:

Por ser uma língua estrangeira, travessia que me colheu desde a infância para me imergir na alteridade. É a língua do Outro que se tornou íntima. Foi ela que supriu as carências da língua de infância. De refúgio ao abrigo, os livros dos outros habitaram a minha solidão. Eles transformaram a minha veemência em tenacidade. Em resistência. Eles me inscreveram inteiramente no caminho da escrita. Agora, a minha leva minha deriva de memória o mais longe possível das tensões. A escrita se impõe em última liberdade de l'in-famille. Ela é a minha partição expatriada, minha fuga de todo fechamento. (MOKEDDEM, 2003, p. 219-220) $)^{40}$.

No entanto, como é frequente nos estudos literários pós-coloniais, a língua não é desprovida de uma utilização política. Se a língua francesa adquire conotações particulares para as mulheres, por vezes ambíguas pois ela é composta por uma forte dose de libertação, o árabe não é mais desprovido de elementos contraditórios -

\footnotetext{
${ }^{39}$ Texto original : Je me dis que je ne peux pas mordre le sein qui m'a nourrie, je ne peux pas trahir quelque chose qui est en moi. (...) Je n'ai pas choisi cette langue mais elle est mienne - alors je dis cela en boutade quand j'ai un public français - c'est elle qui est venue me coloniser, pour mon bonheur — la langue, pas le colonisateur - et maintenant puisqu'elle m'a possédée, qu'elle fait partie de moi, c'est moi qui, à présent, vais la coloniser et lui dire la complexité de la situation algérienne et de l' "algérianiser ». Voilà, c'est comme cela qu'elle est devenue mienne. (HELM, 2000, p. 42, 43)

${ }^{40}$ Texto original : Et puis c'est une langue étrangère, traversière, qui m'a cueillie dès l'enfance pour me frotter à l'altérité. C'est la langue de l'Autre qui est devenue l'intime. C'est elle qui a pallié les carences de la langue de l'enfance. De refuge en repaire, les livres des autres ont habité ma solitude. Ils ont transformé ma véhémence en ténacité. En résistance. Ils m'ont inscrite à part, entière, dans le chemin de l'écriture. À présent la mienne porte ma dérive de mémoire au plus loin des crispations. L'écriture s'impose en ultime liberté de l'infamille. Elle est ma partition d'expatriée, ma fugue de tout enfermement.
}

(MOKEDDEM, 2003, p. 219-220).

Nota dos tradutores: l'infamille: sentido de "em família". 


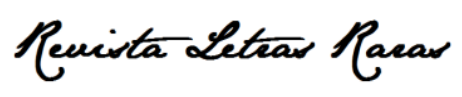

ISSN: 2317-2347 - v. 6, n. 2 (2017)

particularmente na Argélia. Nas últimas décadas, a política de arabização na Argélia acentuou o fosso entre os adeptos de uma arabização geral e, por outro lado, os adeptos de reivindicações berberes e francófonas. Em 1990, a Assembleia popular argelina votou na generalização da língua árabe - uma das reivindicações do FIS - estabelecendo um confronto entre francófonos de um lado e do outro os defensores da tradição - sob a qual aparece subjacente o status da mulher. A esse propósito, Malika Mokeddem mostrou como toda imposição que contraria a liberdade de expressão, que implica obrigatoriamente na livre escolha da língua de expressão. É isso o que ela declara em um artigo publicado no jornal Le Monde: "e se os tiranos, de espíritos retrógrados a temem e querem proibi-la, pois a veem coberta de luz e sempre gestante de liberdade." (ASSOULINE, 1992, p. 203) $)^{41}$. A partir disso, podemos concluir que a escrita descentrada de Malika Mokeddem se torna uma escrita nômade, no sentido onde ela transgride restrições, representa uma nova concepção da dicotomia tradicional e estereotipada de uma escrita feminina diante de uma dita escrita masculina. A condição sexual não é menos penetrante, mas, longe de se tornar a reivindicação prioritária, ela se integra no seio de um discurso que tende à desconstrução de todas as categorias arbitrárias, centralizadoras e eventualmente normativas.

\section{Referências}

ALLAMI, N. Voilées, dévoilées. In: Être femme dans le monde arabe. Paris: L'Harmattan, 1988.

ASSOULINE, F. Musulmanes: une chance pour l'Islam. Paris: Flammarion, 1992.

BHABBA, H. The location of culture. Londres: Routledge, 1994.

ABOU, S. L'identité culturelle. Paris: Anthropos, 1986.

BEAUVOIR, S. Le deuxième sexe. Paris: Gallimard, 1976.

BOURDIEU, P. La domination masculine. Paris: Seuil, 2002.

BOURGET, C. Coran et Tradition islamique dans la littérature maghrébine. Paris: Karthala, 2002.

\footnotetext{
${ }^{41}$ Texto original: Le Monde: Et si des tyrans, des esprits rétrogrades la redoutent tant et veulent la frapper d'interdit, c'est qu'ils la savent nimbée de lumière et toujours en gésine de liberté (ASSOULINE, 1992, p. 203).
} 


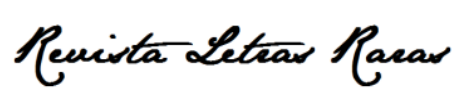

ISSN: $2317-2347$ - v. 6, n. 2 (2017)

BRAIDOTTI, R. Nomadic Subjects. New-York: Columbia, 1994.

CHAULET-ACHOUR, C. Algériennes dans l'écriture. Paris: Séguier, 1999.

CHAULET-ACHOUR, C. Féminin / Masculin : Lectures et représentations. CergyPontoise: Université de Cergy-Pontoise, 2000.

CIXOUS, H. La venue à l'écriture. Paris: Union Générale d'Éditions, 1986.

DJEBAR, A. L'amour, la fantasia. Paris, Albin Michel, 1985.

DJEBAR, A. Loin de Médine. Paris, Albin Michel, 1991.

DJEBAR, A. Vaste est la prison. Paris: Albin Michel, 1995.

GLISSANT, E. Introduction à une poétique du divers. Paris: Gallimard, 1996.

HELM, Y. Malika Mokeddem: oralité, nomadisme, écriture et transgression. In: Présence Francophone. Québec : Université de Sherbrooke, 1999.

HELM, Y. Malika Mokeddem : envers et contre tout. Paris: L'Harmattan, 2000.

HORER, S.; Socquet, J. La création étouffée. Paris: Pierre Horay, 1973.

HUSTON, N; SEBBAR, L. Lettres parisiennes. Histoires d'exil. Paris: Bernard Barrault, 1986.

IRIGARAY, L. Entre Orient et Occident. Paris: Grasset, 1999.

LACOSTE-DUJARDIN, C. Des mères contre les femmes. Maternité et patriarcat au maghreb. Paris: Ed. La Découverte, 1985.

LARONDE, M. L'écriture décentrée. La langue de l'Autre dans le roman contemporain. Paris: L'Harmattan, 1996.

MAALOUF, A. Les identités meurtrières. Paris: Grasset, 1998.

MERNISSI, F. Marruecos a través de sus mujeres. Madrid: Ediciones del Oriente y del Mediterráneo, 1991.

- Sueños en el umbral: memorias de una niña del harén. Barcelona: Muchnik Editores, 1995.

- El harén en Occidente. Madrid: Espasa-Calpe, 2003.

MINCES, J. La génération suivante. Paris: Flammarion, 1986.

MOHANTY, Ch.; RUSSO A.; TORRES, L. Third World and the Politics of Feminism. Bloomington: Indiana University Press, 1991.

MOKEDDEM, M. Les hommes qui marchent. Paris: Grasset, 1990.

— Le siècle des sauterelles. Paris: Ramsay, 1992.

- Des rêves et des assassins. Paris: Grasset, 1995.

- La nuit de la lézarde. Paris: Grasset, 1998.

— La transe des insoumis. Paris: Grasset, 2003.

MOURA, J.M. Littératures francophones et théorie postcoloniale. Paris: PUF, 1999.

— La critique postcoloniale, étude des spécificités. In: Paris: Africultures, 2000. 


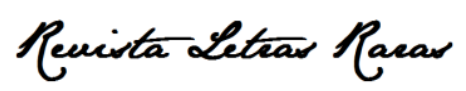

ISSN: $2317-2347$ - v. 6, n. 2 (2017)

SEGARRA, M. Leur pesant de poudre. Romancières francophones du Maghreb, Paris: L'Harmattan, 1997.

— Feminismo y crítica postcolonial. In: Feminismo y crítica literária. Barcelona: Icaria, 2000 .

SCHOR, N. French Feminism is a Universalism. In: Différences, A Journal of Feminist Cultural Studies. Duke : Duke University Press, 1995.

VEGA, M.J.; CARBONELL, N. La literatura comparada. Principios y métodos. Madrid: Gredos, 1998.

YAGUELLO, M. Les mots et les femmes. Paris: Petite Bibliothèque Payot 1978.

ZOUARI, F. Ce voile qui déchire la France. Paris : Ramsay, 2004.

Data de recebimento: 30/10/2017

Data de aceite: $28 / 11 / 2017$ 